\title{
Serial Liquid Biopsy
}

National Cancer Institute

\section{Source}

National Cancer Institute. Serial Liquid Biopsy. NCI Thesaurus. Code C151934.

Multiple liquid biopsies made over time. 